\title{
Glutathione-S-transferase M1 regulation of diesel exhaust particle-induced pro-inflammatory mediator expression in normal human bronchial epithelial cells
}

Weidong $\mathrm{Wu}^{1 *}$, David B Peden ${ }^{1}$, Rob McConnell ${ }^{2}$, Scott Fruin ${ }^{2}$ and David Diaz-Sanchez ${ }^{3}$

\begin{abstract}
Background: Diesel exhaust particles (DEP) contribute substantially to ambient particulate matter (PM) air pollution in urban areas. Inhalation of PM has been associated with increased incidence of lung disease in susceptible populations. We have demonstrated that the glutathione S-transferase M1 (GSTM1) null genotype could aggravate DEP-induced airway inflammation in human subjects. Given the critical role airway epithelial cells play in the pathogenesis of airway inflammation, we established the GSTM1 deficiency condition in primary bronchial epithelial cells from human volunteers with GSTM1 sufficient genotype (GSTM1+) using GSTM1 shRNA to determine whether GSTM1 deficiency could exaggerate DEP-induced expression of interleukin-8 (IL-8) and IL-1 $\beta$ proteins. Furthermore, the mechanisms underlying GSTM1 regulation of DEP-induced IL-8 and IL-1 $\beta$ expression were also investigated.

Methods: IL-8 and IL-1 $\beta$ protein levels were measured using enzyme-linked immunosorbent assay. GSTM1 deficiency in primary human bronchial epithelial cells was achieved using lentiviral GSTM1 shRNA particles and verified using real-time polymerase chain reaction and immunoblotting. Intracellular reactive oxygen species (ROS) production was evaluated using flow cytometry. Phosphorylation of protein kinases was detected using immunoblotting.

Results: Exposure of primary human bronchial epithelial cells (GSTM1+) to 25-100 $\mu \mathrm{g} / \mathrm{ml}$ DEP for $24 \mathrm{~h}$ significantly increased IL-8 and IL-1 $\beta$ protein expression. Knockdown of GSTM1 in these cells further elevated DEP-induced IL-8 and IL-1 $\beta$ expression, implying that GSTM1 deficiency aggravated DEP-induced pro-inflammatory response. DEP stimulation induced the phosphorylation of extracellular signal-regulated kinase (ERK) and Akt, the downstream kinase of phosphoinositide 3-kinase (PI3K), in GSTM1+ bronchial epithelial cells. Pharmacological inhibition of ERK kinase and PI3K activity blocked DEP-induced IL-8 and IL-1 $\beta$ expression. DEP-induced ERK and Akt phosphorylation could be increased by GSTM1 knockdown. In addition, pretreatment of HBEC with the antioxidant N-acetyl cysteine significantly inhibited DEP-induced ERK and Akt phosphorylation, and subsequent IL-8 and IL-1 $\beta$ expression.
\end{abstract}

Conclusion: GSTM1 regulates DEP-induced IL-8 and IL-1 $\beta$ expression in primary human bronchial epithelial cells by modulation of ROS, ERK and Akt signaling.

Keywords: Diesel exhaust particles, ROS, GSTM1, ERK, Akt

\footnotetext{
* Correspondence: Weidong_Wu@med.unc.edu

${ }^{1}$ Center for Environmental Medicine, Asthma, and Lung Biology, University of

North Carolina, Chapel Hill, NC 27599, USA

Full list of author information is available at the end of the article
} 


\section{Background}

Diesel exhaust particles (DEP) emitted during the combustion of diesel fuel are an important contributor to the levels of particulate matter (PM) air pollution in urban areas. These particles comprise a carbonaceous core to which organic and inorganic compounds, such as polycyclic aromatic hydrocarbons (PAHs), nitro and oxygenated derivatives of PAHs, heterocyclic compounds, aldehydes, aliphatic hydrocarbons, and heavy metals, can be adsorbed. Epidemiological and experimental studies have shown that DEP inhalation is associated with elevated incidence of diverse respiratory disorders including pulmonary inflammation, increased susceptibility to respiratory infections, increased risk of lung cancer, and exacerbation of asthma and chronic obstructive pulmonary diseases [1-4]. However, the mechanisms underlying DEP-induced pulmonary disorders have not yet been adequately elucidated.

The pathogenesis of many respiratory diseases is characterized by airway inflammation, which is driven by a plethora of pro-inflammatory mediators released from airway resident and infiltrating inflammatory cells [5]. The airway epithelium represents the interface between the external environment and the tissue of the airway wall [6]. The production of pro-inflammatory mediators from airway epithelium plays a critical role in the pathogenesis of pulmonary diseases [5,7]. Exposure to air pollution particles has been shown to evoke pro-inflammatory mediator production in airway epithelial cells [8-10]. It has been demonstrated that the pro-inflammatory effect of air particles is affected by many factors, such as particle size, concentration, composition, duration of exposure, and copollutants [11]. Increasing evidence indicates that the host susceptibility factors may also play an important role in air pollutant-induced lung inflammation [12,13]. Susceptibility to the adverse effects of air pollutants is an intrinsic trait most probably related to genotypes [14]. Animal studies have shown that prolonged low-dose DEP exposure induces airway inflammatory responses that differ remarkably among mouse strains with different genetic backgrounds of oxidative stress response [15]. It has been proposed that host responses to DEP are regulated by a balance between antioxidant defenses and pro-inflammatory responses [16]. The lung has multiple anti-oxidative defense systems including the glutathione $S$-transferases (GSTs) [17]. The GSTs are a supergene family of phase II conjugating enzymes that consist of a number of sub-classes such as GSTM1 and GSTP1, and catalyze the conjugation of reduced glutathione with hydrophobic electrophiles and reactive oxygen species (ROS) [18]. GSTM1 is mapped to the GST mu 1 gene cluster on chromosome 1p13.3. Genetic variants that regulate the availability and functionality of the GST enzymes determine the levels of oxidative effects in the airway and associated injury [19]. GST gene polymorphisms, particularly the GSTM1 null genotype, are frequent in the population with reported frequencies from 18 to $66 \%$ in different ethnic groups [20]. The deletion variants or null alleles that exist for the GSTM1 gene present biochemically as a failure to express protein [21,22]. Individuals with the GSTM1 null genotype completely lack the GSTM1 enzyme activity and their susceptibility to asthma and lower lung function is increased [23-25].

Our previous studies have demonstrated that the GSTM1 null genotype is associated with aggravation of airway inflammation in human subjects exposed to diverse air toxicants including ozone, endotoxin, DEP, and second hand smoke [14,26-28], implying that GSTM1 deficiency might be a risk factor in air pollutant-induced lung diseases. It should be noted that these in vivo studies investigated only the association of GSTM1 genotype with pollutant-induced lung inflammation, and they cannot exclude the contribution of other genetic factors in the modulation of response to air pollutants. To our knowledge, no mechanistic studies have been conducted to examine the function of GSTM1 protein in the pathogenesis of airway inflammation. Given the critical role airway epithelial cells play in the pathogenesis of airway inflammation, we manipulated GSTM1 levels in primary human bronchial epithelial cells (HBEC) from human volunteers with GSTM1 sufficient (GSTM1+) genotype using GSTM1 shRNA to determine whether GSTM1 deficiency could modulate DEP-induced pro-inflammatory response, herein, the over-expression of interleukin- 8 (IL- 8$)$ and IL- $1 \beta$ proteins. In addition, the mechanisms whereby GSTM1 regulated DEP-induced IL-8 and IL-1 $\beta$ protein expression were also examined.

\section{Results and discussion}

DEP exposure increases IL-8 and IL-1 $\beta$ protein expression in GSTM1+ primary human bronchial epithelial cells

IL-8 is a major mediator of acute pulmonary inflammation as a chemoattractant for neutrophils $[29,30]$. IL-1 $\beta$ is also an important mediator of the inflammatory response that can also induce production of other proinflammatory cytokines and chemokines [31]. Increased levels of IL- 8 and IL-1 $\beta$ have been observed in inflammatory lung diseases $[32,33]$. In this study we used IL-8 and IL-1 $\beta$ as the biomarker of pro-inflammatory response of airway epithelial cells to DEP stimulation. Exposure of HBEC to $100 \mu \mathrm{g} / \mathrm{ml}$ DEP for up to $24 \mathrm{~h}$ did not result in significant alterations in cell viability, as assessed by assay of lactate dehydrogenase activity released into the culture medium. As shown in Figure 1A, exposure of HBEC to $25-100 \mu \mathrm{g} / \mathrm{ml}$ DEP for $24 \mathrm{~h}$ induced a significant increase in IL-8 protein expression $(\mathrm{F}=92.36, \mathrm{p}<0.01)$. Similarly, DEP stimulation also induced a dose-dependent increase 


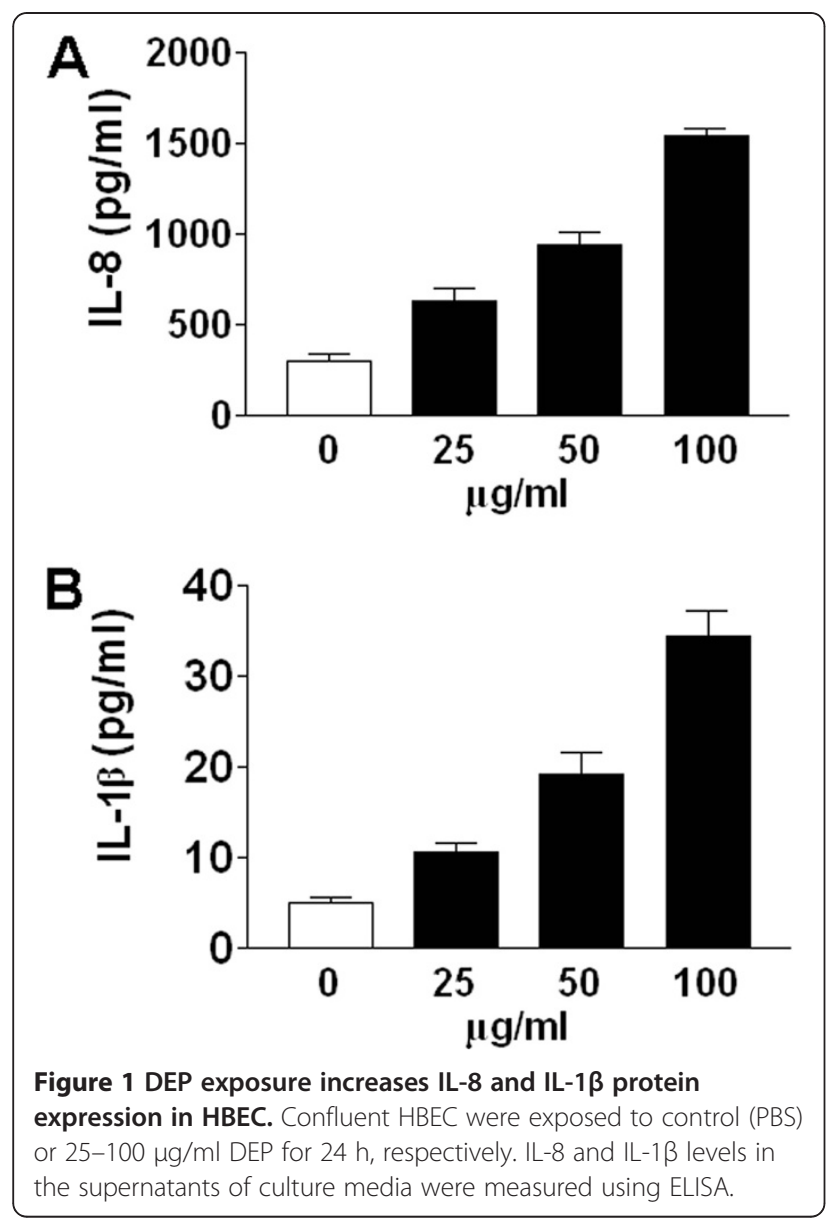

in IL-1 $\beta$ protein expression in HBEC (Figure 1B, $\mathrm{F}=46.22, \quad \mathrm{P}<0.01)$. These results indicate that DEP stimulation up-regulates IL- 8 and IL- $1 \beta$ protein expression in GSTM1+ primary human bronchial epithelial cells.

In regard to the environmental relevance of the DEP concentration used in this study, a recent study has calculated that a plausible real-world exposure could result in an inhalational exposure of $0.9 \mathrm{mg}$ of DEP in certain settings such as bus depots, garages and tunnels [34]. With an approximately 5\% deposition throughout the conducting airways in a periciliary volume of 50-500 $\mu \mathrm{l}$ this amount of DEP would result in a concentration between 90 and $900 \mu \mathrm{g} / \mathrm{ml}$. Therefore, the DEP doses used in this study $(25-100 \mu \mathrm{g} / \mathrm{ml})$ are relevant to real environmental exposure situations.

The DEP used in this study was suspended in molecular-grade water. It has been reported that these DEP contain both redox metals and redox active organic substances [35]. The metals appear to be tightly bound to particles and are not extractable into water. To define the contribution of metallic component to DEP-induced biological effect, normal human bronchial epithelial cells were pretreated with $100 \mu \mathrm{M}$ deferoxamine for $2 \mathrm{~h}$ prior to $50 \mu \mathrm{g} / \mathrm{ml}$ DEP stimulation. It was shown that deferoxamine had little inhibitory effect on DEP-induced ROS production, ERK activation, as well as IL-8 expression (data not shown). The particles also contain electrophiles which exhibit both water and dichloromethane solubility. To determine the contribution of aqueous extract to DEP-induced IL-8 expression in HBEC, we centrifuged the DEP suspension at $13000 \mathrm{rpm}$ for $30 \mathrm{~min}$ and determined the effect of the supernatant of DEP suspension on IL-8 expression in HBEC. It was found that there was no significant difference in IL-8 induction between DEP aqueous extract and control (data not shown). This suggested that water soluble components of DEP played a minimal role in DEP-induced proinflammatory response.

\section{GSTM1 knockdown significantly increases DEP-induced IL-8 and IL-1 $\beta$ protein expression in HBEC}

We have demonstrated that GSTM1 null genotype is associated with aggravation of DEP-induced airway inflammation in human subjects. Given that the airway epithelium plays an important role in regulating pulmonary inflammatory responses and GSTM1 expression has been detected in human airway cells [36], we assumed that modulation of GSTM1 expression levels in airway epithelial cells might affect DEP-induced IL-8 and IL-1 $\beta$ expression. To test this assumption, we established the GSTM1 deficiency condition in vitro in HBEC (GSTM1+) using lentiviral GSTM1 shRNA particles and determined its effect on DEP-induced IL- 8 and IL- $1 \beta$ expression. This in vitro approach provided the opportunity of examining the contribution of GSTM1 deficiency to DEP-induced pro-inflammatory response. HBEC (GSTM1+) were infected with lentiviral scrambled or GSTM1 shRNA particles, respectively, prior to DEP treatment. As shown in Figure 2A and $\mathrm{B}$, infection of HBEC (GSTM1+) with 10 moi of lentiviral GSTM1 shRNA particles caused significant reduction of GSTM1 mRNA levels (by 77\%) as well as GSTM1 protein as compared to the cells infected with lentiviral scrambled shRNA particles. Then, GSTM1 sufficient or knockdown cells were treated with PBS control or $50 \mu \mathrm{g} / \mathrm{ml}$ DEP for $24 \mathrm{~h}$. Levels of IL- 8 and IL-1 $\beta$ proteins in the supernatant of culture medium were measured with ELISA and expressed as fold over control. As expected, DEP stimulation increased IL-8 expression in HBEC infected with control (scrambled) shRNA particles (Figure 2B). By comparison, DEPinduced IL-8 production was further enhanced in the cells infected with lentiviral GSTM1 shRNA particles (Figure 2B). Similarly, knockdown of GSTM1 also increased DEP-induced IL-1 $\beta$ expression (Figure 2C). Taken together, these results indicated that GSTM1 deficiency increased DEP-induced IL-8 and IL-1 $\beta$ 
Figure 2 GSTM1 knockdown enhanced DEP-induced IL-8 and IL-1 $\beta$ expression in HBEC. A and B, HBEC were infected with lentiviral scrambled or GSTM1 shRNA particles (10 moi) for $24 \mathrm{~h}$, respectively. The cells were lysed for GSTM1 mRNA measurement using RT-PCR ( ${ }^{*} P<0.01$ )or GSTM1 protein determination using immunoblotting. Infected HBEC with lentiviral scrambled or GSTM1 shRNA particles were treated with PBS control or $50 \mu \mathrm{g} / \mathrm{ml}$ DEP for $24 \mathrm{~h}$. Levels of IL-8 (C) and IL-1 $\beta$ (D) proteins in the supernatant of culture media were determined using ELISA and expressed as fold over control (DEP vs. PBS control in scrambled or GSTM1 shRNA group, respectively). ${ }^{*} P<0.05$, compared to DEP treatment in the scrambled shRNA group.

expression in HBEC, which was consistent with the in vivo observation that linked GSTM1 null genotype to aggravation of DEP-induced airway inflammation.

The results that we present on the effect of shRNAmediated knockdown of GSTM1 on the expression of the inflammatory proteins were compared to their respective controls because inter-experiment variability in the response of the cells is substantial. There are multiple factors that contribute to this variability, starting with the fact that this study was conducted on primary cultures of human airway epithelial cells, derived from several donor subjects, over a period of many months. Genetics, age of the culture, passage numbers, state of activation of the cells, etc. are all known to contribute significantly as determinants of the magnitude of the response of these cells to stimulation.

The ERK and PI3K/Akt signaling pathways regulate DEP-induced IL-8 and IL-1 $\beta$ expression in HBEC

The inflammatory responses initiated by diverse external stimulatory signals are usually regulated by activated intracellular kinases in responsive cells [37]. The rapid amplification of the initiating signal is correlated with a number of downstream protein kinases. Protein kinases have been shown to play a crucial role in the regulation of inflammatory mediator expression in the airways [38]. Previous studies have shown that the involvement of mitogen-activated protein kinases (MAPKs), including extracellular signal-regulated kinase (ERK), c-Jun $\mathrm{NH}_{2}-$ terminal kinase (JNK), and p38 kinase pathways, and the PI3K/Akt signaling cascade, in DEP-induced up-regulation of inflammatory mediator genes is cell type-specific, and also varies greatly with pro-inflammatory mediators examined. For example, Takizawa et al. showed that DEPs increased intracellular adhesion molecule-1 expression through $\mathrm{p} 38$, but not ERK, in the transformed human bronchial epithelial cell line BEAS-2B [39]. In contrast, Boland et al. demonstrated that DEP stimulated granulocyte-macrophage colony-stimulating factor production mainly through ERK, and to a lesser extent, through p38 in another human bronchial epithelial cell 
line 16-HBE [40]. In addition, Li et al. found that DEP extracts could activate JNK in a human macrophage cell line THP-1[41]. In a mouse epidermal cell line DEP exposure modestly activated JNK, but had little effect on ERK and p38 [42]. In this study, we examined whether these protein kinases are involved in DEP-induced IL-8 and IL-1 $\beta$ expression in primary human bronchial epithelial cells. Phosphorylation of MAPKs was measured using phospho-specific antibodies against JNK, p38, and ERK, respectively. As shown in Figure 3A, exposure of HBEC to $50 \mu \mathrm{g} / \mathrm{ml}$ DEP induced a marked phosphorylation of ERK, but not p38 or JNK (data not shown), which peaked at $1 \mathrm{~h}$ of exposure. To further determine the role of ERK pathway in DEP-induced IL- 8 and IL-1 $\beta$ production, we used the specific inhibitor of the ERK kinase U0126 to pretreat cells prior to DEP stimulation. HBEC were pre-incubated with $20 \mu \mathrm{M}$ U0126 for $30 \mathrm{~min}$ prior to treatment with $50 \mu \mathrm{g} / \mathrm{ml}$ DEP for $24 \mathrm{~h}$. IL- 8 and IL-1 $\beta$ protein levels were measured with ELISA. As shown in Figure 3B, pretreatment of HBEC with U0126 significantly blocked DEP-induced IL-8 and IL-1 $\beta$ expression, indicating that the ERK signaling pathway was involved in DEP-induced IL-8 and IL-1 $\beta$ expression.

Next, we examined the involvement of the PI3K/Akt signaling pathway in DEP-induced IL-8 and IL-1 $\beta$ expression in DEP-treated HBEC. Activation of the PI3K/ Akt signaling was determined by measuring the phosphorylation of Akt [43]. As demonstrated in Figure 3C, DEP stimulation $(50 \mu \mathrm{g} / \mathrm{ml})$ induced an acute and sustained Akt phosphorylation, indicating that the PI3K/ Akt pathway was activated by DEP stimulation. To further determine whether this pathway was involved in DEP-induced IL- 8 and IL- $1 \beta$ expression, wortmannin, the selective inhibitor of the PI3K, was used to pretreat HBEC. HBEC were pretreated with $1 \mu \mathrm{M}$ wortmannin for $30 \mathrm{~min}$ before further treatment with $50 \mu \mathrm{g} / \mathrm{ml} \mathrm{DEP}$ for $24 \mathrm{~h}$. As shown in Figure 3D, wortmannin pretreatment inhibited DEP-induced IL- 8 and IL-1 $\beta$ expression. These results showed that the PI3K/Akt signaling pathway is activated by DEP stimulation, further upregulating IL- 8 and IL- $1 \beta$ expression.

It has been proposed that the expression of inflammatory genes can be regulated at both transcriptional and posttranscriptional levels $[44,45]$. Exactly how the ERK and PI3K/Akt signaling pathways up-regulate DEPinduced IL- 8 and IL-1 $\beta$ expression remains to be defined.

\section{Knockdown of GSTM1 further increases DEP-induced ERK and Akt activities}

The possible mechanisms underlying GSTM1-modulated lung inflammation are largely unknown. GSTM1 detoxifies electrophilic compounds by catalyzing their conjugation with reduced GSH. It is presumed that intermediate

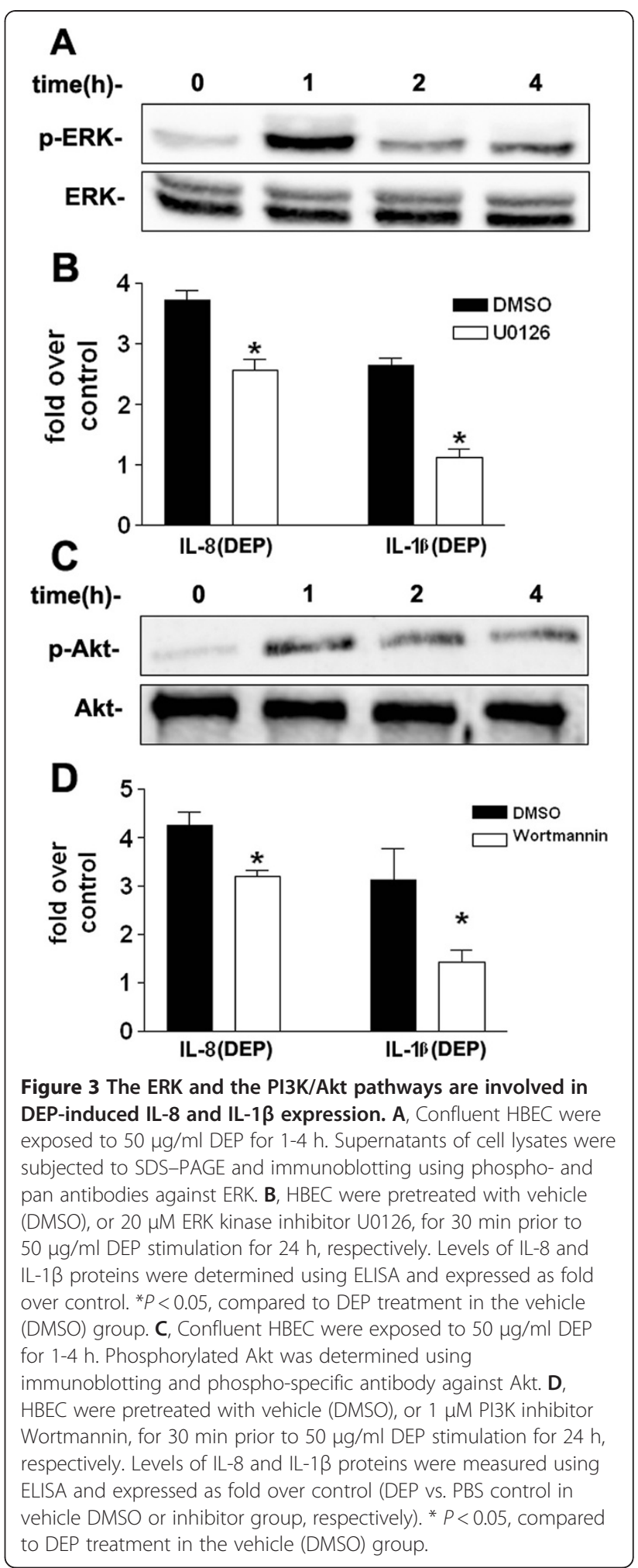

electrophilic metabolites, arising in the first phase of detoxification, are not metabolized in GSTM1-null asthma patients and are not excreted. These intermediate metabolites may damage cells and generate oxidative stress, 
and thereby contribute to the pathogenesis of asthma [46]. In addition to this well-characterized catalytic activity, recent evidence has suggested that GSTM1 may control oxidative stress and inflammation through the regulation of intracellular signaling pathways by its effects on certain small molecules or by protein-protein interactions with critical kinases. The ligand-binding capacity of GSTM1 results in the negative regulation of signaling pathways through sequestration of signaling kinases [47].

As demonstrated previously, GSTM1, ERK and Akt were all involved in the regulation of DEP-induced IL-8 and IL-1 $\beta$ expression in HBEC. We hypothesized that enhancement of DEP-induced IL-8 and IL-1 $\beta$ protein expression by GSTM1 deficiency might be achieved through modulation of ERK and Akt activities. To test this hypothesis, we reduced GSTM1 expression levels in HBEC with GSTM1 shRNA and examined ERK and Akt phosphorylation induced by DEP exposure. HBEC with sufficient or deficient GSTM1 were treated with $50 \mu \mathrm{g} / \mathrm{ml}$ DEP for $1 \mathrm{~h}$. Phosphorylation of ERK and Akt was determined using immunoblotting, respectively. In the cells expressing sufficient GSTM1 DEP stimulation increased both ERK and Akt phosphorylation (Figure 4A and B). In contrast, in the cells with reduced GSTM1 expression the phosphorylation levels of ERK and Akt induced by DEP exposure were modestly enhanced, indicating that GSTM1 deficiency could promote DEP-induced ERK and Akt activation.

The mechanisms whereby GSTM1 deficiency modulated DEP-induced ERK and PI3K/Akt activation were under speculation. Given the oxidative property of many air pollutants and the feature of ROS as the second messenger in intracellular signaling network [48,49], we envisioned that the anti-oxidant GSTM1 might affect ERK and Akt activity through modulation of intracellular ROS production in HBEC exposed to DEP. The two main organic compounds adsorbed on DEP, PAHs and quinones, have been demonstrated to contribute to ROS production through enzymatic or non-enzymatic reactions [41,50-54]. DEP-induced intracellular ROS production was measured in this study. It was shown that $50 \mu \mathrm{g} / \mathrm{ml}$ DEP could significantly increase levels of ROS after $1 \mathrm{~h}$ stimulation (Figure 5A). To further examine the effect of GSTM1 deficiency on DEP-induced ROS production, we reduced intracellular GSTM1 levels using lentiviral GSTM1 shRNA particles and then compared
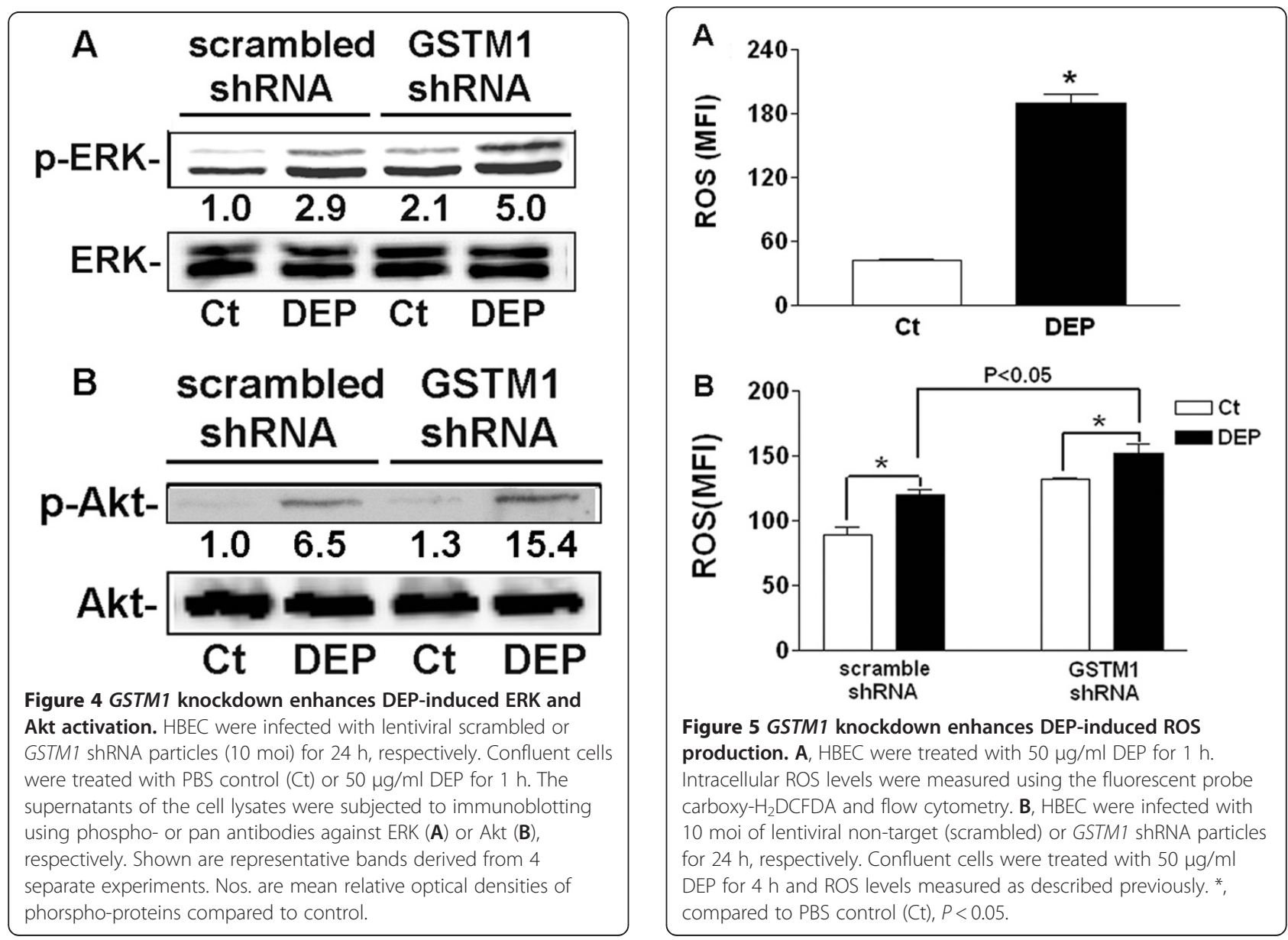
the difference in ROS production from HBEC expressing sufficient or deficient GSTM1 after DEP treatment. GSTM1 sufficient or deficiency cells were treated with $50 \mu \mathrm{g} / \mathrm{ml} \mathrm{DEP}$ for $4 \mathrm{~h}$ and ROS levels measured. As shown in Figure $5 \mathrm{~B}$, in the cells infected with control shRNA DEP stimulation markedly increased ROS production. In contrast, in the cells containing GSTM1 shRNA DEP-induced ROS production was further increased, indicating that GSTM1 deficiency can increase the production of intracellular ROS in DEP-treated HBEC, possibly resulting in enhanced ERK and PI3K/ Akt activation.

Effect of the antioxidant NAC on intracellular ROS levels, ERK and Akt phosphorylation, and IL- 8 and IL-1 $\beta$ expression

To further examine the involvement of ROS in DEPinduced cellular responses as described previously, we pretreated HBEC with $\mathrm{N}$-acetyl-L-cysteine (NAC) prior to DEP stimulation $(50 \mu \mathrm{g} / \mathrm{ml})$. The antioxidant NAC is a thiol-reducing agent that can antagonize cellular ROS. Levels of phosphorylated ERK and Akt, and IL-8 and IL$1 \beta$ protein were measured. As shown in Figure 6, pretreatment with NAC significantly inhibited DEP-induced ERK and Akt phosphorylation, as well as IL- 8 and IL-1 $\beta$ expression. Taken together, these data suggested that ROS played an important role in DEP-induced ERK and Akt activation, and subsequent up-regulation of IL-8 and IL-1 $\beta$. NAC is derivative of the amino acid cysteine and can be proposed to boost levels of glutathione, the substrate of GSTM1. Therefore, the fact that NAC supplementation inhibited DEP-induced oxidative and proinflammatory effect supported the role GSTM1 played against airway inflammation.

\section{Conclusion}

This in vitro study using primary human bronchial epithelial cells provides experimental evidence in support of the notion that the GSTM1 null phenotype is a risk factor for DEP-induced airway inflammation. Specifically, knockdown of GSTM1 leads to enhanced IL- 8 and IL-1 $\beta$ expression in primary human bronchial epithelial cells exposed to DEP. Furthermore, this study demonstrates that GSTM1 knockdown increases DEP-induced IL-8 and IL-1 $\beta$ expression through ROS-associated ERK and Akt activation.

\section{Methods}

\section{Reagents}

5-(and-6)-carboxy-2', 7'-dichlorodihydrofluorescein diacetate (carboxy- $\mathrm{H}_{2}$ DCFDA) was purchased from Invitrogen Corporation (Carlsbad, CA). Deferoxamine (DFO) mesylate was purchased from Sigma-Aldrich (St. Louis, MO). N-acetyl-L-cysteine (NAC), U0126 and wortmannin

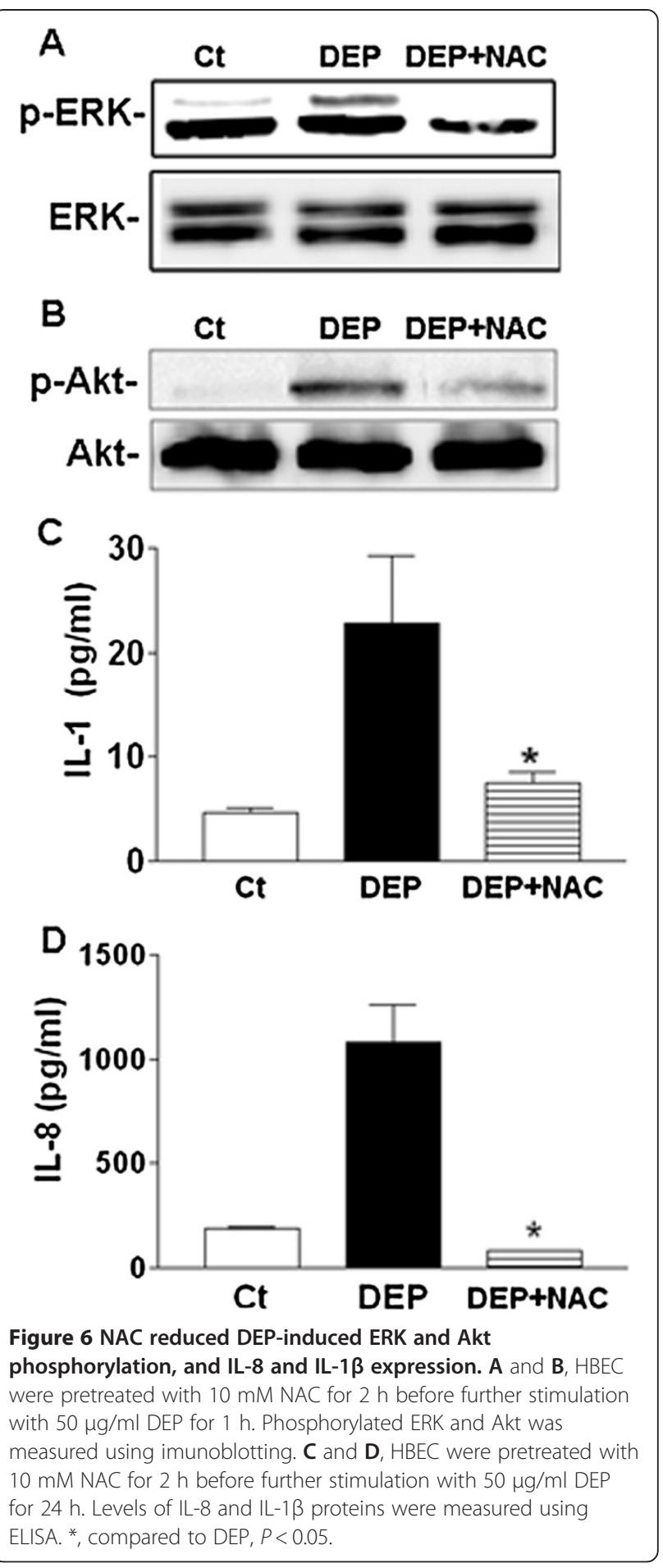

were obtained from EMD Chemicals (Gibbstown, NJ). The rabbit antibodies against phospho-ERK and Akt, and pan ERK and Akt were obtained from Cell Signaling Technology (Beverly, MA). Horseradish peroxidase (HRP)-conjugated goat anti-rabbit antibody was obtained from Santa Cruz Biotechnology (Santa Cruz, CA). IL-8 and IL-1 $\beta$ ELISA assay kits were purchased 
from eBioscience (San Diego, CA). Chemiluminescence reagents were obtained from Thermo Scientific (Huntsville, AL). MISSION lentiviral non-target shRNA and GSTM1 shRNA transduction particles were purchased from Sigma-Aldrich Corporation (St. Louis, MO).

\section{Cell culture}

Primary human bronchial epithelial cells (HBEC) were obtained from healthy adult human volunteers by brush biopsy of the mainstem bronchus using a cytology brush during fiberoptic bronchoscopy, conducted under a protocol approved by the Committee on the Protection of the Rights of Human Subjects at the University of North Carolina at Chapel Hill. HBEC were initially plated in supplemented bronchial epithelial cell basal medium $(0.5 \mathrm{ng} / \mathrm{ml}$ human epidermal growth factor, $0.5 \mu \mathrm{g} / \mathrm{ml}$ hydrocortisone, $5 \mu \mathrm{g} / \mathrm{ml}$ insulin, $10 \mu \mathrm{g} / \mathrm{ml}$ transferrin, $0.5 \mu \mathrm{g} / \mathrm{ml}$ epinephrine, $6.5 \mathrm{ng} / \mathrm{ml}$ triiodothyronine, $50 \mu \mathrm{g} / \mathrm{ml}$ gentamycin, $50 \mathrm{ng} / \mathrm{ml}$ amphotericin-B, $52 \mu \mathrm{g} / \mathrm{ml}$ bovine pituitary extract and $0.1 \mathrm{ng} / \mathrm{ml}$ retinoic acid) on tissue culture flasks and expanded in the same growth media.

\section{DEP sample and preparation}

The DEP used in this study was one (DEP5) of the seven DEP samples generated at the US Environmental Protection Agency's National Risk Management Research Laboratory, Research Triangle Park, North Carolina, USA, using a $30 \mathrm{~kW}(40 \mathrm{hp})$ 4-cylinder indirect injection Deutz diesel engine (Model BF4M1008) under load of a $22.3 \mathrm{~kW}$ (30 hp) Saylor-Beall air compressor (Model 707). The exhaust was diluted with ambient air (3:1) to near ambient temperatures $\left(\sim 35^{\circ} \mathrm{C}\right)$ and directed to a small $4.2 \mathrm{~m}^{3} / \mathrm{min}\left(150 \mathrm{ft}^{3} / \mathrm{min}\right)$ rated Dustex bag house (Model T6-35-9) containing Nomex felt bags. The bags were periodically reversed pulsed using compressed air to remove the accumulated DEP which were collected from the hopper at the end of each day and stored refrigerated $\left(41^{\circ} \mathrm{C}\right)$ in glass sample jars for the in vitro assays [35]. The percentage of extractable organic matter (EOM) of DEP was about 31\%. These particles contained high concentrations of lower-molecular-weight polycyclic aromatic hydrocarbon, phenanthrene, fluoranthene, pyrene, and metals [34].

DEP stored in the glass sample jar, as described previously, were suspended in molecular grade water (Mediatech Inc, Manassas, VA) to make a stock solution of $1 \mathrm{mg} / \mathrm{ml}$, and sonicated just before incubated with HBEC. The particle size was less than $0.45 \mu \mathrm{m}$.

\section{Enzyme linked immunosorbent assay (ELISA)}

After exposure of HBEC to DEP for $24 \mathrm{~h}$, the culture media were collected and centrifuged. Levels of IL-8 and IL-1 $\beta$ proteins in the supernatants were measured with human IL-8 and IL-1 $\beta$ ELISA kits following the manufacturer's instructions.

\section{Immunoblotting}

HBEC exposed to DEP were washed twice with ice-cold phosphate-buffered saline (PBS), and then lysed in RIPA buffer (1x PBS, 1\% nonidet P-40, 0.5\% sodium deoxycholate, $0.1 \%$ SDS, and protease inhibitors: $20 \mu \mathrm{g} / \mathrm{ml}$ leupeptin, $20 \mu \mathrm{g} / \mathrm{ml}$ aprotinin, $0.5 \mathrm{mM}$ phenylmethylsulfonyl fluoride, $200 \mu \mathrm{M}$ sodium orthovanadate, and $20 \mathrm{mM}$ sodium fluoride). The supernatants of cell lysates were subjected to SDS-PAGE. Proteins were transferred onto nitrocellulose membrane. Membrane was blocked with 5\% nonfat milk, washed briefly, incubated with primary antibody at $4^{\circ} \mathrm{C}$ overnight, followed by incubating with corresponding HRP-conjugated secondary antibody for $1 \mathrm{~h}$ at room temperature. Immunoblot images were detected using chemiluminescence reagents and the Fujifilm LAS3000 imaging system (Fuji Medical Systems, USA).

\section{GSTM1 knockdown assay}

$5 \times 10^{4}$ HBEC were placed in a 12 well plate and grown overnight. 10 moi (multiplicity of infection) of lentiviral non-target (scrambled) or GSTM1 shRNA particles in $0.5 \mathrm{ml}$ bronchial epithelial growth medium were incubated with HBEC for $24 \mathrm{~h}$. The infection medium was removed and replaced with fresh growth medium. Upon confluence, HBEC were lysed and assayed for GSTM1 mRNA levels and GSTM1 protein, respectively.

\section{Real-time polymerase chain reaction}

HBEC infected with lentiviral scrambled or GSTM1 shRNA particles were lysed with TRIZOL reagent (Invitrogen Corporation, Carlsbad, CA) and RNA extracted. Total RNA (100 ng), $0.5 \mathrm{mM}$ NTP (Pharmacia, Piscataway, NJ), $5 \mu \mathrm{M}$ random hexaoligonucleotide primers (Pharmacia, NJ), $10 \mathrm{U} / \mu \mathrm{l}$ RNase inhibitor (Promega, $\mathrm{CA})$, and $10 \mathrm{U} / \mu \mathrm{l}$ Moloney murine leukemia virus RT (GIBCO-BRL Life Technologies) were incubated in a $40^{\circ} \mathrm{C}$ water bath for $1 \mathrm{~h}$ in $50 \mu \mathrm{l}$ of $1 \mathrm{x}$ PCR buffer to synthesize first-strand cDNAs. The reverse transcription was inactivated by heating at $92^{\circ} \mathrm{C}$ for $5 \mathrm{~min}$. Oligonucleotide primer pairs and fluorescent probes for GSTM1 and actin were obtained from Applied Biosystem (Carlsbad, CA).

Quantitative fluorogenic amplification of cDNA was performed using the ABI Prism 7500 Sequence Detection System (Perkin-Elmer, CA). The relative abundance of GSTM1 mRNA levels was calculated using the difference between the cycle threshold (CT) of the GSTM1 mRNA sequence and the reference actin mRNA sequence. 


\section{Measurement of intracellular reactive oxygen species (ROS)}

The intracellular formation of ROS in HBEC was detected using the fluorescent ROS probe carboxy$\mathrm{H}_{2}$ DCFDA. Carboxy- $\mathrm{H}_{2}$ DCFDA is a cell-permeant indicator for ROS that is nonfluorescent until the acetate groups are removed by intracellular esterases and oxidation occurs within the cell [55]. The green fluorescence produced by HBEC is proportional to the amount of ROS produced. Briefly, confluent HBEC were preincubated with $20 \mu \mathrm{M}$ carboxy- $\mathrm{H}_{2} \mathrm{DCFDA}$ at $37^{\circ} \mathrm{C}$ for $1 \mathrm{~h}$ prior to exposure to $50 \mu \mathrm{g} / \mathrm{ml} \mathrm{DEPs}$. Cells were detached by $0.05 \%$ trypsin-EDTA, washed once with PBS, suspended in $0.5 \mathrm{ml}$ PBS and put on ice before determination of green fluorescence intensity. Flow cytometry was performed with a FACSORT (BectonDickinson, Miami, FL, USA) by using an argon-ion laser (wavelength $488 \mathrm{~nm}$ ). The FACSORT was calibrated with Calibrite beads before each use, and 6000 events were counted for all sample runs. Relative cell size and density/granularity were quantified by analyzing light-scatter properties using CellQuest software (Becton-Dickinson), namely forward scatter for cell size and side scatter for density/granularity, and recording the mean fluorescence intensities for each.

\section{Statistical analysis}

Data are presented as means \pm SE. Data were evaluated using nonparametric paired $t$ tests with the overall $\alpha$ level set at 0.05. One-way ANOVA was used to analyze the dose-dependent trends of IL- 8 and IL- $1 \beta$ protein expression.

\section{Abbreviations \\ DEP: Diesel exhaust particles; GST: Glutathione S-transferase; ROS: Reactive oxygen species; MAPKs: Mitogen-activated protein kinases; ERK: Extracellular signal-regulated kinase; PI3K: Phosphoinositide 3-kinase; PAHs: Polycyclic aromatic hydrocarbons; JNK: C-Jun $\mathrm{NH}_{2}$-terminal kinase; HBEC: Human bronchial epithelial cells; PBS: Phosphate-buffered saline.}

\section{Competing interests}

The authors declare that they have no competing interests.

\section{Authors' contributions}

WW, DBP, RM, and DDS designed this study. WW performed the experiments, acquisition and statistical analysis of data. The manuscript was written by WW and revised by DBP, RM, DDS, and SF. All authors read, corrected and approved the manuscript.

\section{Acknowledgements}

We greatly appreciate the manuscript review by Dr. James Samet, and technical support by Lisa Dailey, Melanie J. Jardim, Arantza EigurenFernandez, and Wenli Zhang. This work was supported by the National Institute of Health R01ES016535 and U19AI077437 and the United States Environmental Protection Agency Cooperative Agreement CR83346301. Although the research described in this article has been funded in part by the United States Environmental Protection Agency through cooperative agreement CR83346301 with the Center for Environmental Medicine, Asthma and Lung Biology at the University of North Carolina at Chapel Hill, it has not been subjected to the Agency's required peer and policy review, and therefore does not necessarily reflect the views of the Agency and no official endorsement should be inferred. Mention of trade names or commercial products does not constitute endorsement or recommendation for use.

\section{Author details}

${ }^{1}$ Center for Environmental Medicine, Asthma, and Lung Biology, University of North Carolina, Chapel Hill, NC 27599, USA. ${ }^{2}$ Department of Preventive Medicine, University of Southern California, Los Angeles, CA 90033, USA. ${ }^{3}$ Environmental Public Health Division, National Health and Environmental Effects Research Laboratory, US Environmental Protection Agency, Chapel Hill, NC 27599, USA.

Received: 25 July 2011 Accepted: 1 August 2012

Published: 6 August 2012

\section{References}

1. Gowdy K, Krantz QT, Daniels M, Linak WP, Jaspers I, Gilmour MI: Modulation of pulmonary inflammatory responses and antimicrobial defenses in mice exposed to diesel exhaust. Toxicol Appl Pharmacol 2008, 229:310-319.

2. Saxon A, Diaz-Sanchez D: Air pollution and allergy: you are what you breathe. Nat Immunol 2005, 6:223-226.

3. McCreanor J, Cullinan P, Nieuwenhuijsen MJ, Stewart-Evans J, Malliarou E, Jarup L, Harrington R, Svartengren M, Han IK, Ohman-Strickland P, Chung KF, Zhang J: Respiratory effects of exposure to diesel traffic in persons with asthma. N Engl J Med 2007, 357:2348-2358.

4. Ris C: U.S. EPA health assessment for diesel engine exhaust: a review. Inhal Toxicol 2007, 19(Suppl 1):229-239.

5. Raphael GD, Metcalfe DD: Mediators of airway inflammation. Eur J Respir Dis Suppl 1986, 147:44-56.

6. Crystal RG, Randell SH, Engelhardt JF, Voynow J, Sunday ME: Airway epithelial cells: current concepts and challenges. Proc Am Thorac Soc 2008, 5:772-777.

7. Holgate ST: The airway epithelium is central to the pathogenesis of asthma. Allergol Int 2008, 57:1-10

8. Devalia JL, Bayram H, Rusznak C, Calderon M, Sapsford RJ, Abdelaziz MA Wang J, Davies RJ: Mechanisms of pollution-induced airway disease: in vitro studies in the upper and lower airways. Allergy 1997, 52(discussion 57-48):45-51.

9. Krishna MT, Chauhan AJ, Frew AJ, Holgate ST: Toxicological mechanisms underlying oxidant pollutant-induced airway injury. Rev Environ Health 1998, 13:59-71.

10. Takizawa H, Ohtoshi T, Kawasaki S, Abe S, Sugawara I, Nakahara K, Matsushima K, Kudoh S: Diesel exhaust particles activate human bronchial epithelial cells to express inflammatory mediators in the airways: a review. Respirology 2000, 5:197-203.

11. Aust AE, Ball JC, Hu AA, Lighty JS, Smith KR, Straccia AM, Veranth JM, Young WC: Particle characteristics responsible for effects on human lung epithelial cells. Res Rep Health Eff Inst 2002, 110:1-65. discussion 67-76.

12. Annesi-Maesano I, Agabiti N, Pistelli R, Couilliot MF, Forastiere F: Subpopulations at increased risk of adverse health outcomes from air pollution. Eur Respir J Supp/ 2003, 40:57s-63s.

13. Kleeberger SR: Genetic aspects of pulmonary responses to inhaled pollutants. Exp Toxicol Pathol 2005, 57(Suppl 1):147-153.

14. Gilliland FD, Li YF, Saxon A, Diaz-Sanchez D: Effect of glutathione-Stransferase $\mathrm{M} 1$ and $\mathrm{P} 1$ genotypes on xenobiotic enhancement of allergic responses: randomised, placebo-controlled crossover study. Lancet 2004, 363:119-125.

15. Li YJ, Kawada T, Takizawa H, Azuma A, Kudoh S, Sugawara I, Yamauchi Y, Kohyama T: Airway inflammatory responses to oxidative stress induced by prolonged low-dose diesel exhaust particle exposure from birth differ between mouse BALB/c and C57BL/6 strains. Exp Lung Res 2008, 34:125-139.

16. Takizawa H: Diesel exhaust particles and their effect on induced cytokine expression in human bronchial epithelial cells. Curr Opin Allergy Clin Immunol 2004, 4:355-359.

17. Rahman I, Biswas SK, Kode A: Oxidant and antioxidant balance in the airways and airway diseases. Eur J Pharmacol 2006, 533:222-239.

18. Hayes JD, Pulford DJ: The glutathione S-transferase supergene family: regulation of GST and the contribution of the isoenzymes to cancer chemoprotection and drug resistance. Crit Rev Biochem Mol Biol 1995, 30:445-600. 
19. Islam T, Berhane K, McConnell R, Gauderman WJ, Avol E, Peters JM, Gilliland FD: Glutathione-S-transferase (GST) P1, GSTM1, exercise, ozone and asthma incidence in school children. Thorax 2009, 64:197-202.

20. Carlsten C, Sagoo GS, Frodsham AJ, Burke W, Higgins JP: Glutathione S-transferase M1 (GSTM1) polymorphisms and lung cancer: a literaturebased systematic HuGE review and meta-analysis. Am J Epidemio/ 2008, 167:759-774.

21. Board PG: Biochemical genetics of glutathione-S-transferase in man. Am J Hum Genet 1981, 33:36-43.

22. Seidegard J, Vorachek WR, Pero RW, Pearson WR: Hereditary differences in the expression of the human glutathione transferase active on transstilbene oxide are due to a gene deletion. Proc Natl Acad Sci U S A 1988, 85:7293-7297.

23. Gilliland FD, Gauderman WJ, Vora H, Rappaport E, Dubeau L: Effects of glutathione-S-transferase M1, T1, and P1 on childhood lung function growth. Am J Respir Crit Care Med 2002, 166:710-716

24. Tamer L, Calikoglu M, Ates NA, Yildirim H, Ercan B, Saritas E, Unlu A, Atik U: Glutathione-S-transferase gene polymorphisms (GSTT1, GSTM1, GSTP1) as increased risk factors for asthma. Respirology 2004, 9:493-498.

25. Hanene $C$, Jihene $L$, Jamel A, Kamel H, Agnes H: Association of GST genes polymorphisms with asthma in Tunisian children. Mediators Inflamm 2007 2007:19564

26. Dillon MA, Harris B, Hernandez ML, Zou B, Reed W, Bromberg PA, Devlin RB, Diaz-Sanchez D, Kleeberger S, Zhou H, Lay JC, Alexis NE, Peden DB: Enhancement of systemic and sputum granulocyte response to inhaled endotoxin in people with the GSTM1 null genotype. Occup Environ Med 2011, 68:783-785.

27. Alexis NE, Zhou H, Lay JC, Harris B, Hernandez ML, Lu TS, Bromberg PA, Diaz-Sanchez D, Devlin RB, Kleeberger SR, Peden DB: The glutathione-Stransferase Mu 1 null genotype modulates ozone-induced airway inflammation in human subjects. J Allergy Clin Immunol 2009, 124:1222-1228. e1225.

28. Gilliland FD, Li YF, Gong H Jr, Diaz-Sanchez D: Glutathione s-transferases $\mathrm{M} 1$ and $\mathrm{P} 1$ prevent aggravation of allergic responses by secondhand smoke. Am J Respir Crit Care Med 2006, 174:1335-1341.

29. Strieter RM: Interleukin-8: a very important chemokine of the human airway epithelium. Am J Physiol Lung Cell Mol Physiol 2002, 283:L688-689.

30. Standiford TJ, Kunkel SL, Strieter RM: Interleukin-8: a major mediator of acute pulmonary inflammation. Reg Immunol 1993, 5:134-141.

31. Edwards MR, Mukaida N, Johnson M, Johnston SL: IL-1 beta induces IL-8 in bronchial cells via NF-kappaB and NF-IL6 transcription factors and can be suppressed by glucocorticoids. Pulm Pharmacol Ther 2005, 18:337-345.

32. Chung KF: Inflammatory mediators in chronic obstructive pulmonary disease. Curr Drug Targets Inflamm Allergy 2005, 4:619-625.

33. Berger M: Inflammatory mediators in cystic fibrosis lung disease. Allergy Asthma Proc 2002, 23:19-25.

34. Cheng WY, Currier J, Bromberg PA, Silbajoris R, Simmons SO, Samet JM: Linking oxidative events to inflammatory and adaptive gene expression induced by exposure to an organic particulate matter component. Environ Health Perspect 2012, 120:267-274.

35. Shinyashiki M, Eiguren-Fernandez A, Schmitz DA, Di Stefano E, Li N, Linak WP, Cho SH, Froines JR, Cho AK: Electrophilic and redox properties of diesel exhaust particles. Environ Res 2009, 109:239-244.

36. Cantlay AM, Smith CA, Wallace WA, Yap PL, Lamb D, Harrison DJ: Heterogeneous expression and polymorphic genotype of glutathione S-transferases in human lung. Thorax 1994, 49:1010-1014.

37. Lee M, Goodbourn S: Signalling from the cell surface to the nucleus. Essays Biochem 2001, 37:71-85.

38. Adcock IM, Chung KF, Caramori G, Ito K: Kinase inhibitors and airway inflammation. Eur J Pharmacol 2006, 533:118-132.

39. Takizawa H, Abe S, Ohtoshi T, Kawasaki S, Takami K, Desaki M, Sugawara I, Hashimoto S, Azuma A, Nakahara K, Kudoh S: Diesel exhaust particles up-regulate expression of intercellular adhesion molecule-1 (ICAM-1) in human bronchial epithelial cells. Clin Exp Immunol 2000, 120:356-362.

40. Boland S, Bonvallot V, Fournier T, Baeza-Squiban A, Aubier M, Marano F: Mechanisms of GM-CSF increase by diesel exhaust particles in human airway epithelial cells. Am J Physiol Lung Cell Mol Physiol 2000, 278:L25-32.

41. Li N, Wang M, Oberley TD, Sempf JM, Nel AE: Comparison of the prooxidative and proinflammatory effects of organic diesel exhaust particle chemicals in bronchial epithelial cells and macrophages. J Immunol 2002, 169:4531-4541.
42. Ma C, Wang J, Luo J: Activation of nuclear factor kappa B by diesel exhaust particles in mouse epidermal cells through phosphatidylinositol 3-kinase/Akt signaling pathway. Biochem Pharmacol 2004, 67:1975-1983.

43. Downward J: PI 3-kinase, Akt and cell survival. Semin Cell Dev Biol 2004 15:177-182.

44. Fan J, Heller NM, Gorospe M, Atasoy U, Stellato C: The role of posttranscriptional regulation in chemokine gene expression in inflammation and allergy. Eur Respir J 2005, 26:933-947.

45. Holtmann H, Winzen R, Holland P, Eickemeier S, Hoffmann E, Wallach D, Malinin NL, Cooper JA, Resch K, Kracht M: Induction of interleukin-8 synthesis integrates effects on transcription and mRNA degradation from at least three different cytokine- or stress-activated signal transduction pathways. Mol Cell Biol 1999, 19:6742-6753.

46. Wu W, Peden DB, Diaz-Sanchez D: Role of GSTM1 in resistance to lung inflammation. Free Radic Biol Med 2012, 53:721-729.

47. Mcllwain CC, Townsend DM, Tew KD: Glutathione S-transferase polymorphisms: cancer incidence and therapy. Oncogene 2006, 25:1639-1648.

48. Ciencewicki J, Trivedi S, Kleeberger SR: Oxidants and the pathogenesis of lung diseases. J Allergy Clin Immunol 2008, 122:456-468. quiz 469-470.

49. Savaraj N, Wei Y, Unate H, Liu PM, Wu CJ, Wangpaichitr M, Xia D, Xu HJ, Hu SX, Tien Kuo M: Redox regulation of matrix metalloproteinase gene family in small cell lung cancer cells. Free Radic Res 2005, 39:373-381.

50. Baulig A, Garlatti M, Bonvallot V, Marchand A, Barouki R, Marano F, BaezaSquiban A: Involvement of reactive oxygen species in the metabolic pathways triggered by diesel exhaust particles in human airway epithelial cells. Am J Physiol Lung Cell Mol Physiol 2003, 285:L671-679.

51. Ng D, Kokot N, Hiura T, Faris M, Saxon A, Nel A: Macrophage activation by polycyclic aromatic hydrocarbons: evidence for the involvement of stress-activated protein kinases, activator protein-1, and antioxidant response elements. J Immuno/ 1998, 161:942-951.

52. Park JY, Shigenaga MK, Ames BN: Induction of cytochrome P4501A1 by 2,3,7,8-tetrachlorodibenzo-p-dioxin or indolo(3,2-b)carbazole is associated with oxidative DNA damage. Proc Natl Acad Sci U S A 1996, 93:2322-2327

53. Sagai M, Saito H, Ichinose T, Kodama M, Mori Y: Biological effects of diesel exhaust particles. I. In vitro production of superoxide and in vivo toxicity in mouse. Free Radic Biol Med 1993, 14:37-47.

54. Kumagai $Y$, Arimoto T, Shinyashiki M, Shimojo N, Nakai Y, Yoshikawa T, Sagai $\mathrm{M}$ : Generation of reactive oxygen species during interaction of diesel exhaust particle components with NADPH-cytochrome $\mathrm{P} 450$ reductase and involvement of the bioactivation in the DNA damage. Free Radic Biol Med 1997, 22:479-487.

55. Cathcart R, Schwiers E, Ames BN: Detection of picomole levels of hydroperoxides using a fluorescent dichlorofluorescein assay. Anal Biochem 1983, 134:111-116.

doi:10.1186/1743-8977-9-31

Cite this article as: Wu et al:: Glutathione-S-transferase $\mathrm{M} 1$ regulation of diesel exhaust particle-induced pro-inflammatory mediator expression in normal human bronchial epithelial cells. Particle and Fibre Toxicology 2012 9:31.

\section{Submit your next manuscript to BioMed Central and take full advantage of:}

- Convenient online submission

- Thorough peer review

- No space constraints or color figure charges

- Immediate publication on acceptance

- Inclusion in PubMed, CAS, Scopus and Google Scholar

- Research which is freely available for redistribution 